\title{
Material properties of high-mobility TCOs and application to solar cells
}

\author{
Florian Ruske $^{1 *}$, Steffi Schönau ${ }^{1}$, Sven Ring $^{2}$, Sebastian Neubert ${ }^{2}$, Bernd Stannowski ${ }^{2}$, Volker \\ Sittinger ${ }^{3}$, Stefan Götzendörfer ${ }^{4}$, Bernd Rech ${ }^{1}$ \\ ${ }^{1}$ Helmholtz-Zentrum Berlin für Materialien und Energie, Institute Silicon Photovoltaics, \\ Kekuléstraße 5, D-12489 Berlin, Germany \\ ${ }^{2}$ Helmholtz-Zentrum Berlin für Materialien und Energie, PVcomB, Schwarzschildstraße 3, D-12489 \\ Berlin, Germany \\ ${ }^{3}$ Fraunhofer-Institute for Surface Engineering and Thin Films (IST), Bienroder Weg 54e, 38108 \\ Braunschweig, Germany \\ ${ }^{4}$ Berliner Glas Surface Technology, Giengener Straße 16, 89428 Syrgenstein
}

\begin{abstract}
The benefit of achieving high electron mobilities in transparent conducting oxides (TCOs) is twofold: they first exhibit superior optical properties, especially in the NIR spectral range, and secondly their low resistivity enables the usage of thinner films. Remarkably high mobilities can be obtained in Al-doped zinc oxide by post-deposition annealing under a protective layer. The procedure has not only shown to increase mobility, but also strongly reduces sub-bandgap absorption.

Extensive optical, electrical and structural characterization is carried out in the films in order to clarify the microscopic origins of the changes in material properties. While the annealing of defect states, most likely deep acceptors, seems clear, earlier results also suggest some influence of grain boundaries. Tailing, on the contrary, seems to be linked to extended defects.

In application to a-Si:H/ $\mu \mathrm{c}-\mathrm{Si}: \mathrm{H}$ thin film solar cells the films have already shown to increase spectral response. When reducing the film thickness, the main challenge is to provide a suitable light trapping scheme. Normally this is achieved by a wet chemical etching step in diluted $\mathrm{HCl}$, which provides a surface structure with suitable light scattering properties. Therefore a TCO-independent light scattering approach using textures glass was applied in conjunction with the high mobility zinc oxide. The substrate enables the use of very thin TCO layers with a strongly reduced parasitic absorption.
\end{abstract}

Keywords: High mobility TCO, ZnO:Al, post-deposition annealing, protective layer, a-Si:H/ $\mu \mathrm{c}-\mathrm{Si}: \mathrm{H}$ tandem cells, light trapping, textured glass substrate

\section{INTRODUCTION}

Annealing procedures are widely applied to transparent conducting oxides (TCOs) in order to increase their electrical conductivity and optical transmission. In the case of indium oxide [1] or titanium oxide [2], annealing is often carried out to crystallize films deposited in a partial or complete amorphous phase, which increases the electrical quality of the films. In other cases annealing is used to form dense inorganic material from films deposited from the liquid phase, for instance by spray pyrolysis or sol-gel coating [3].

In the case of zinc oxide, annealing procedures are known to only result in strong structural changes upon annealing at very high temperatures, but annealing procedures are nevertheless used to optimize electrical and optical properties. For instance annealing can lead to improved properties for films deposited at low substrate temperatures, especially when carried out at moderate temperatures in vacuum[4] or reducing ambient [5,6]. On the contrary annealing at too high temperatures in oxidizing conditions can quickly lead to a deterioration of electrical conductivity by several orders of magnitude [6,7].

\footnotetext{
*florian.ruske@ helmholtz-berlin.de; phone: +49 308062 15487; fax: +49 30806215677
} 
Capping a zinc oxide film with a thin protective layer before annealing allows for thermal treatments at much higher temperatures. Treated films generally show a much improved electron mobility and superior optical properties. Especially parasitic absorption close to the bandedge (bandtails) can be strongly diminished [7-9].

The multiple effects of thermal annealing are still not sufficiently well understood. It is generally accepted that oxygen plays a major role in compensation of carriers and that this effect is partially reversible. Nevertheless the remarkable mobilities and the decreased bandtailing have not been considered in a full picture.

This paper summarizes recent results of investigations into the fundamental effects of thermal annealing on zinc oxide films and applications to solar cells.

\section{EXPERIMENTAL DETAILS}

The $\mathrm{ZnO}: \mathrm{Al}$ films investigated in this work were prepared in different sputtering coaters. The films used for material analysis were prepared in the sputtering chamber of a VAAT VS 400 PS cluster tool by RF magnetron sputtering of a circular (diameter $250 \mathrm{~mm}$ ) ceramic $\mathrm{ZnO}$ target containing one weight percent of $\mathrm{Al}_{2} \mathrm{O}_{3}$. Sputtering was carried out in pure $\mathrm{Ar}$ atmosphere at a flow rate of $40 \mathrm{sccm}$. For all experiments sputtering power was set to $750 \mathrm{~W}$, sputtering pressure was $250 \mathrm{mPa}$ and the target-to-substrate distance was kept at $124 \mathrm{~mm}$. The deposition chamber allows for substrate temperatures from room temperature up to over $500{ }^{\circ} \mathrm{C}$. Eagle Corning XG substrates were used.

After deposition we applied various annealing procedures. In these annealing procedures, the films were treated in a conventional annealing oven under flowing nitrogen at ambient pressure. The temperature was slowly ramped up and down again during the annealing procedure in order to prevent cracking of the films. In some cases the films were coated with a thin layer of amorphous silicon by PECVD prior to the annealing. This procedure has shown to protect the layers from degradation of electrical properties [10] and has led to films with a remarkable carrier mobility. The capping layer can be easily removed after the annealing procedure with a dry etching procedure in a $\mathrm{NF}_{3}$ plasma. In summary the following annealing procedures were applied:

- "Degradation": Annealing at $550{ }^{\circ} \mathrm{C}$ for 24 hours without protection

- “Cap anneal”: Annealing at $650{ }^{\circ} \mathrm{C}$ for 24 hours under a protective layer of a-Si:H

- "2 step anneal": Consecutive application of degradation and cap anneal.

For cell application deposition was carried out on larger substrates in a vertical in-line sputtering system Leybold Optics A600V7 using DC sputtering of a ceramic tube target with 1 wt. $\% \mathrm{Al}_{2} \mathrm{O}_{3}$ doping. While being less versatile in terms of substrate temperature, the coater allows for a very good reproducibility and good homogeneity over a substrate area of $30 \times 30 \mathrm{~cm}^{2}$. Low-iron soda lime glass textured by a wet chemical multi-step process by Berliner Glas was used as substrate. Due to the lower softening point of the glass substrate the annealing temperature was limited to $500{ }^{\circ} \mathrm{C}$ in this case.

Optical spectra of the films were were performed with a dual beam Perkin Elmer High-Performance Lambda 1050 Spectrophotometer using an integrating sphere for both reflection and transmission measurements. The electrical properties of them were analyzed by Hall effect measurements in the van der Pauw geometry using an Ecopia HMS-3000 system.

\section{EFFECT OF ANNEALING PROCEDURES ON ZNO:AL FILMS}

Most effects of the various annealing procedures on the optical and electrical properties of $\mathrm{ZnO}: \mathrm{Al}$ have been reported earlier [7-9, 11]. In general annealing under a protective layer strongly increases the carrier mobility. The final level will depend on deposition conditions and film thickness, record mobilities above $65 \mathrm{~cm}^{2} / \mathrm{Vs}$ can be reached even at high doping levels [7].

Here we investigated the effect of annealing on a series of samples that were deposited at various deposition temperatures (figure 1 left) under pure $\mathrm{Ar}$ gas and at $200{ }^{\circ} \mathrm{C}$ with increasing substitution of $\mathrm{Ar}$ by an $\mathrm{O}_{2} / \mathrm{Ar}(1: 9)$ mixture (figure 1 right). First looking at the films deposited under varying substrate temperature we observe a strong increase of mobility by the "cap anneal" in comparison to the as-deposited state. At the same time the carrier concentration of the films is only slightly increased. 
Annealing without a protective layer ("degraded" samples) on the contrary leads to a strong degradation of electrical properties, with both the mobility and the carrier concentration being reduced significantly. It is interesting to note that the carriers can be partially or completely recovered by a second annealing step under a protective layer (" 2 step anneal"). Resulting films have a slightly lower carrier concentration than films in the as-deposited state at a strongly increased carrier mobility when the deposition was carried out at substrate temperatures below $400{ }^{\circ} \mathrm{C}$ and only slightly higher carrier concentrations than as-deposited films at still higher mobilities for deposition at high temperatures. Depending on the material used and the annealing temperatures, also higher mobilities were observed for a " 2 step anneal" as compared to a direct "cap anneal" [11].

The reversibility of charge carrier degradation upon annealing has also been reported previously for annealing processes under various conditions. Usually films degrade when treated at high temperatures under oxygen, air or nitrogen, while recovery can be achieved under vacuum or reducing ambients (e.g. forming gas). In our case, with the usage of a protective capping layer instead of reducing ambient for recovery, we not only observe a partial or complete recovery of the carrier concentration, but also see a strongly increased mobility.
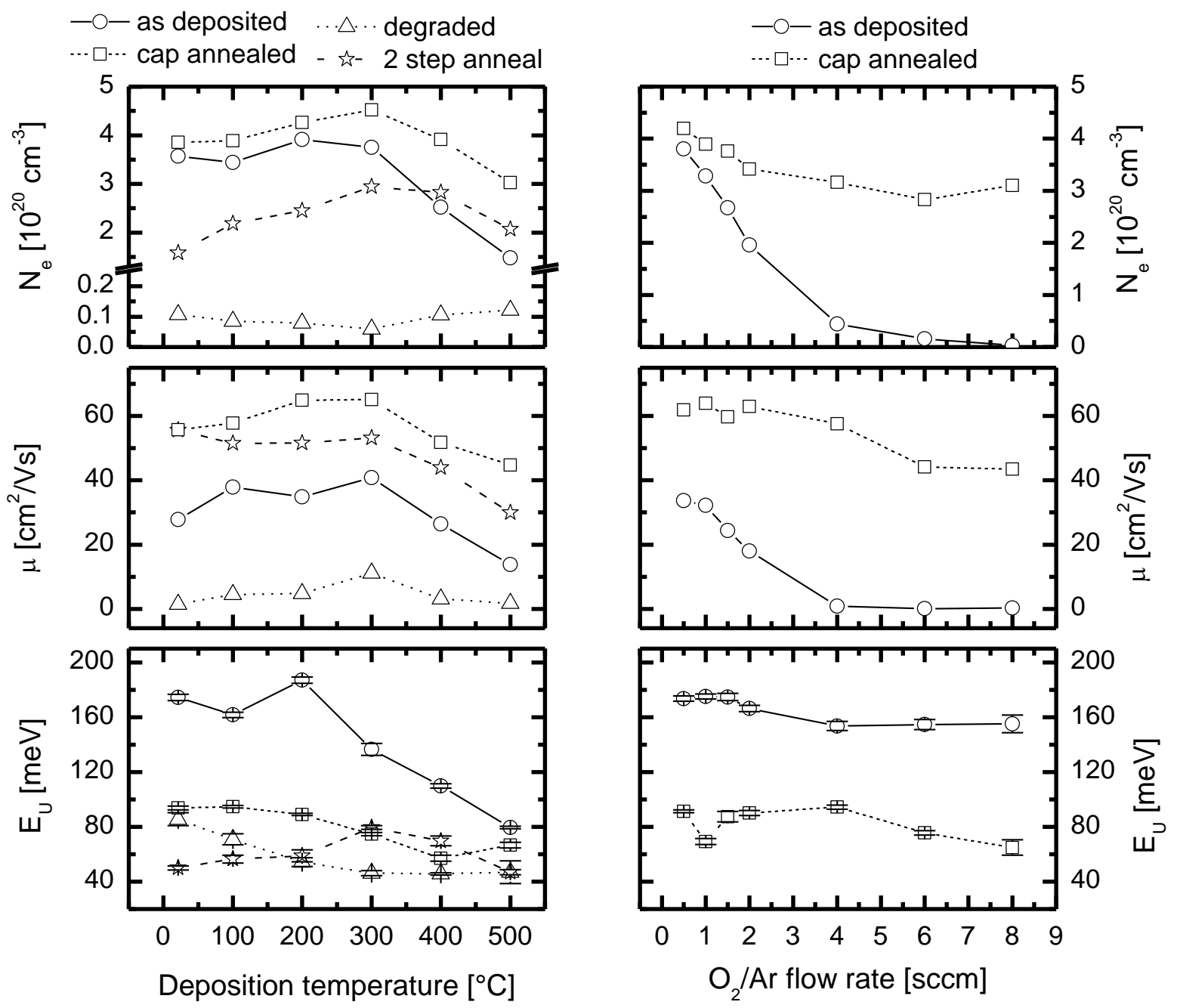

Figure 1: Carrier concentration $\mathrm{N}_{\mathrm{e}}$, mobility $\mu$ and Urbach energies $\mathrm{E}_{\mathrm{U}}$ of samples deposited at various deposition temperatures (left) and with increasing oxygen addition (right). Samples underwent different annealing processes. Details on deposition and treatments can be found in the text.

The mobility increase upon any capped annealing procedure has previously been assumed to be an effect of reduced grain boundary scattering [7]. Additionally, compensation in the bulk is also a very likely reason for reduced carrier 
mobilities [12]. Comparing the cap annealed samples to the as-deposited ones, the strong increase in mobility at only slight increases in carrier concentration is most likely caused by annihilation of intrinsic acceptor levels, most likely both at grain boundaries and in the bulk. Looking at the degraded samples instead the most striking feature is the strong decrease in carrier concentration by more than one order of magnitude.

Due to the partial reversibility of the findings, a precipitation of aluminum at grain boundaries or clusters during degradation cannot be the only effect of annealing, especially as the aluminum content of our samples should be well below the solubility limit of aluminum in zinc oxide. Also a local oxidation of aluminum seems unlikely, as aluminum oxide should be fairly stable. It is therefore likely, that the reduction of the carrier concentration is also caused by the creation of acceptors that partially compensate the n-type conductivity of our samples. The thermodynamic equilibrium of defect levels is known to heavily depend on the annealing ambient and therefore reducing or oxidizing treatments will have a strongly different effect on the acceptor concentration [13,14]. Both the creation of acceptor defects at the grain boundaries as well as in the bulk can explain the observed deterioration of both carrier concentration and mobility due to increased grain boundary scattering [15] or ionized impurity scattering [12], respectively. As in the case of the "cap annealed" samples, also for the "2 step anneal" both effects can explain the observed strong increase in mobility upon recovery of the carrier concentration by acceptor removal.

It should be mentioned, that also intrinsic donors, e.g. oxygen vacancies or zinc interstitials, are believed to contribute to the free carriers. We have no clear evidence, how much they contribute to the carrier concentration in as-deposited samples. Uncapped annealing will rather lead to a decrease of intrinsic donor concentration, but we do not think that the strong decrease of carrier concentration upon uncapped annealing can be solely explained by annihilation of intrinsic donors. It is also unlikely that intrinsic donors play a crucial role in the samples that underwent capped annealing, as doubly charged donors should lead to strong ionized impurity scattering but we observe high mobilities.

Recently more attention was also put into the changes of optical properties caused by the various annealing procedures. In principle the optical properties of $\mathrm{ZnO}$ : Al layers can be well understood as a function of the electrical properties [9]. For highly doped films the bandgap increases upon increasing carrier concentration due to the net effect of bandfilling (Burstein-Moss effect) and bandgap renormalization [16]. At the other end of the visible spectrum, the free carrier absorption in the near infrared region approximately follows the Drude theory or variations thereof [9]. Nevertheless additional absorption, not described by a simple optical model, can be observed close to the bandgap. This absorption mechanism due to band tails has been known for a long time and can be described by the Urbach theory. In order to quantify the effect by deriving an Urbach energy, we first determined the absorption coefficient via

$$
\alpha(E)=-\frac{1}{d} \ln \left(\frac{T(E)}{1-R(E)}\right) .
$$

Afterwards the Urbach energy was derived by fitting a combination of an Urbach expression, i.e. an exponential decay of $\alpha$ with energy, for low photon energies and an error function for high energies [8]. The choice of the error function is motivated by the fact, that the derivative of the absorption coefficient can be expressed as a Gaussian [16].

$$
\alpha(E)=\left\{\begin{array}{cc}
\mathrm{A}\left(\operatorname{erf}\left(\frac{\mathrm{E}-\mathrm{E}_{\mathrm{g}}}{\Gamma}\right)+1\right)+\alpha_{0} & \text { for } \quad E>E_{0} \\
\exp \left(\frac{E-E_{C}}{E_{U}}\right)+\alpha_{0} & \text { for } \quad E \leq E_{0}
\end{array}\right.
$$

$E_{0}$ is the onset energy of the bandtail, $E_{g}$ the bandgap and $E_{U}$ the Urbach energy. $\alpha_{0}$ is a residual absorption and Ec an alternate way to express an amplitude for the Urbach expression. Ec is determined by the demand of the overall function to be continuous. The value of $\mathrm{E}_{0}$ is 50 to $150 \mathrm{meV}$ lower than the bandgap $\mathrm{E}_{\mathrm{g}}$. The slight changes introduced in comparison to [8] resulted in slightly different absolute values for the parameters $\left(\mathrm{E}_{\mathrm{U}}\right.$ changing by a few meV for some samples) but leads to the same overall picture.

It is worthwhile to note, that the examined films are all degenerate n-type conductors, meaning that tailing of the conduction band will not lead to absorption, as all states are expected to be occupied. Instead the determined Urbach energies have to originate from valence band tailing. For the RF sputtered samples we found that the Urbach energy, i.e. 
the amount of parasitic absorption for same film thickness, mainly depends on substrate temperature. For samples deposited at low substrate temperatures Urbach energies above $150 \mathrm{meV}$ are obtained, while this drops to less than $100 \mathrm{meV}$ for samples deposited at $500{ }^{\circ} \mathrm{C}$. It is interesting to note, that addition of oxygen during the deposition process does not lead to a strong change in Urbach energy. For films all deposited at a substrate temperature of $200{ }^{\circ} \mathrm{C}$ oxygen was added to the sputtering process to a concentration of up to $0.5 \%$. While this resulted in a strongly decreased carrier concentration, all films exhibited Urbach energies between 160 and $180 \mathrm{meV}$.

In contrast to these findings, the effect of adding oxygen to the sputtering ambient on the electrical properties of the samples is similar to a thermal treatment in oxidizing environment. As for the degradation procedure, a cap anneal can recover a large fraction of the carriers, so oxidation or precipitation of Al seems unlikely. So also for oxygen addition to the sputtering gas an acceptor creation, as well as elimination of intrinsic donors, seems plausible.

On the contrary, the Urbach energies of degraded samples and samples produced under oxygen addition are strongly different. After degradation the Urbach energy of the sample deposited at $200{ }^{\circ} \mathrm{C}$ dropped to approximately $70 \mathrm{meV}$, while it remained at around $160 \mathrm{meV}$ when oxygen was added to the sputtering gas. So despite the fact, that the Urbach tail has to originate from the valence band, acceptors responsible for the changes in electrical properties cannot be responsible for the strong band tailing. If this was the case, the Urbach energy would have to increase during degradation or by oxygen addition to the process.

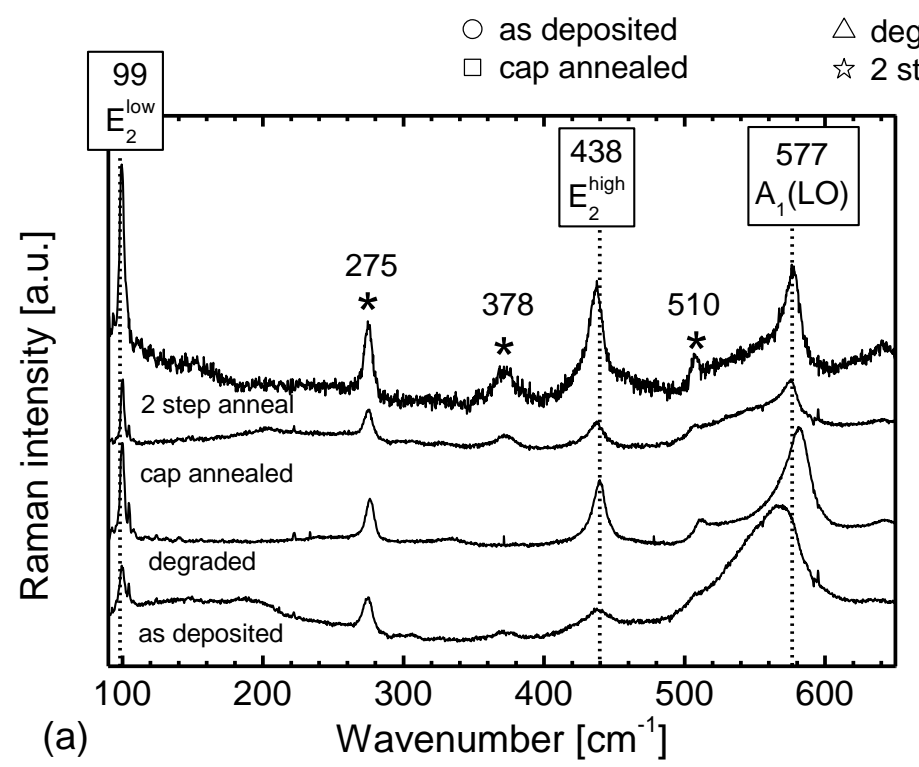

$\triangle$ degraded

2 step annealed

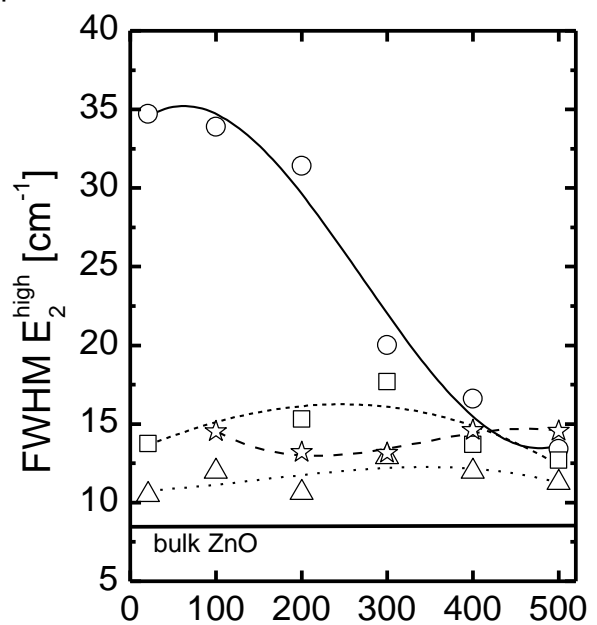

(b) Deposition temperature $\left[{ }^{\circ} \mathrm{C}\right]$

Figure 2: (a) Raman spectra of samples deposited at room temperature in as-deposited state and after various annealing treatments recorded in backscattering geometry using an excitation at $325 \mathrm{~nm}$. (b) FWHM of the $\mathrm{E}_{2}{ }^{\text {(high) }}$ mode for samples deposited under various deposition temperatures and after different annealing procedures.

Evidence for the origin of the bandtails instead comes from Raman measurements [17]. In macroscopic structural characterization by XRD or SEM, the annealing procedures, both capped and uncapped, have not shown to lead to any significant changes apart from very subtle changes to XRD data [11]. Raman measurements on the contrary show strong changes with deposition temperature and annealing. In Figure 2(a) the spectra are plotted for the samples deposited at room temperature in as-deposited state and after various annealing steps. As sputtered films usually show a strong c-axis orientation only the appearance of the $\mathrm{E}_{2}{ }^{\text {(low) }}$, the $\mathrm{E}_{2}{ }^{\text {(high) }}$ and the $\mathrm{A}_{1}(\mathrm{LO})$ modes is expected. Nevertheless we do see more features, most clearly modes at around 275,378 and $510 \mathrm{~cm}^{-1}$. The $378 \mathrm{~cm}^{-1}$ mode is most likely the $\mathrm{A}_{1}(\mathrm{TO})$ mode, that would appear for deviations from c-axis orientation, but the reason for changes during annealing are unclear. For the modes at $275 \mathrm{~cm}^{-1}$ and $510 \mathrm{~cm}^{-1}$ we only want to state that they have also been observed in $\mathrm{ZnO}$ doped with nitrogen [18] and $\mathrm{Fe}, \mathrm{Sb}, \mathrm{Al}$ and $\mathrm{Ga}[19]$.

Our interest in this work is mainly in the intrinsic $\mathrm{E}_{2}^{(\text {high) }}$ mode, for which the FWHM was determined for all samples (figure 2 (b)). The value should be directly linked to the crystallinity of the sample and we do see a strong decrease of the FWHM for both deposition at high temperatures and for all annealing processes. The resemblance to the Urbach energy 
(figure 1 left) is striking. Thus we conclude that mainly a defective crystallinity is responsible for the high Urbach energies for samples deposited at low temperatures in as-deposited state. Due to the fact, that oxygen addition to the growth should result in a strongly changed point defect balance but we do not observe any changes to $\mathrm{E}_{\mathrm{U}}$, we currently assume that extended defects are the reason for the strong Urbach absorption, but can be removed by annealing.

\section{APPLICATION TO SOLAR CELLS}

As seen in the previous section capped annealing of $\mathrm{ZnO}$ :Al films leads to an increase of carrier mobility and parasitic absorption by band tailing can be strongly reduced. While the latter effect directly leads to a better optical performance of the films, the increased mobility also leads to much lower sheet resistances and can be used to further improve optics by the usage of thinner films. The effect is shown in figure 3, where the absorption of films with various thickness but similar sheet resistance is shown as a function of photon energy.

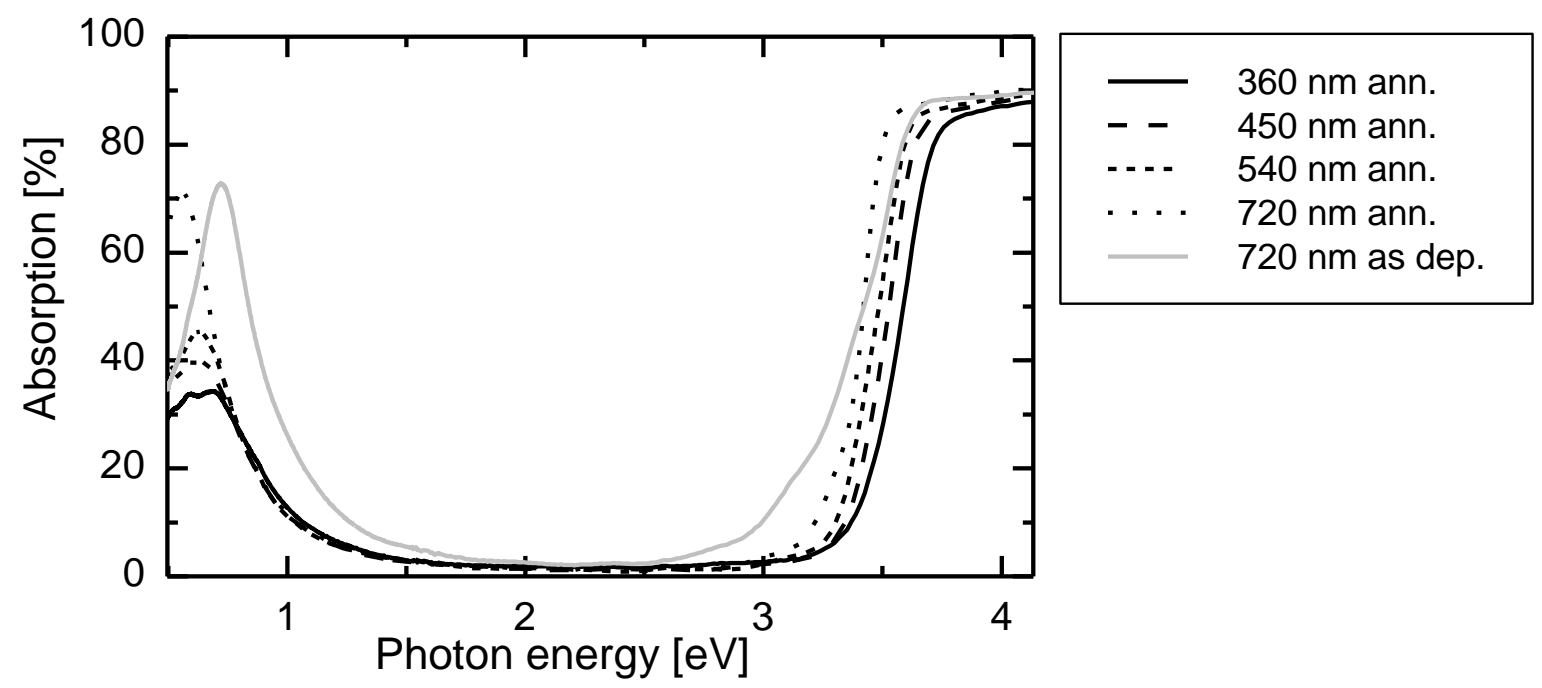

Figure 3: Optical absorption of various $\mathrm{ZnO}$ :Al films with sheet resistances around $7.5 \Omega$. Grey curve denotes a thick sample in as-deposited state, the other curves show films with different thicknesses. Samples usually underwent a 2 -step anneal in which annealing times and temperatures were optimized to achieve similar sheet resistances. Note the absence of band tailing for thermally treated samples.

Table 1: Electrical performance of samples also shown in figure 3. Annealed samples generally exhibit a strongly increased carrier mobility. For thicker samples the annealing procedures could thus be adopted to result in lower carrier concentrations compared to the as-deposited state.

\begin{tabular}{|c|c|c|c|}
\hline Sample & $\begin{array}{c}\text { Sheet resistance } \\
\Omega\end{array}$ & $\begin{array}{c}\mathbf{N e} \\
10^{20} \mathrm{~cm}^{-3}\end{array}$ & $\begin{array}{c}\boldsymbol{\mu} \\
\mathrm{cm}^{2} / \mathrm{Vs}\end{array}$ \\
\hline Ann. $315 \mathrm{~nm}$ & 7.6 & 4.0 & 56.3 \\
\hline Ann. $440 \mathrm{~nm}$ & 7.0 & 3.5 & 58.4 \\
\hline Ann. $530 \mathrm{~nm}$ & 7.7 & 3.0 & 50.4 \\
\hline Ann. $670 \mathrm{~nm}$ & 7.7 & 2.2 & 52.0 \\
\hline Ref. $660 \mathrm{~nm}$ & 7.2 & 3.8 & 32.7 \\
\hline
\end{tabular}

The electrical data of the films shown in figure 3 is listed in table 1 . As can be seen all films exhibit sheet resistances between 7 and $7.7 \Omega$ despite different film thicknesses. This was achieved by varying the annealing procedure so that different carrier concentrations were obtained. Thinner films thus have a higher carrier concentration. Nevertheless this does not lead to more absorption in the near-infrared in the examined samples, as the absorption is generally lower due to the lower film thickness. On the contrary, the higher carrier concentration even results in a larger bandgap due to the 
Burstein-Moss shift and the onset of absorption in the UV spectral range is shifted to higher photon energies. Thus despite the usage of higher carrier concentrations, the optical window of high transmission is even increased for the thinner films.

For the application of the films to thin film silicon solar cells, the usage of thin layers has an inherent disadvantage, though. Tandem cells based on a-Si:H/ $\mu \mathrm{c}-\mathrm{Si}: \mathrm{H}$ rely on efficient light trapping schemes to collect sufficient light for high conversion efficiencies and thus the usage of suitable substrates is mandatory. In record cells usually rough doped $\mathrm{ZnO}$ films are used as TCO front contact, either deposited by LPCVD, which leads to inherently rough film growth, or by sputter deposition with subsequent wet chemical etching. The etching procedure applied to sputtered films can lead to a surface roughness that provides an efficient scattering of light into the active layers deposited onto the TCO. It is common to deposit $\mathrm{ZnO}$ :Al films with thicknesses of $750 \mathrm{~nm}$ and more and to remove approximately $150 \mathrm{~nm}$ by the etching procedure. Although the annealing processes can be applied to etched films [20], for even thinner films the etching process usually yields textures with less efficient light trapping. Thus we tried to decouple the light trapping mechanism from the TCO material itself by the usage of a textures glass substrate, developed by Berliner Glas.

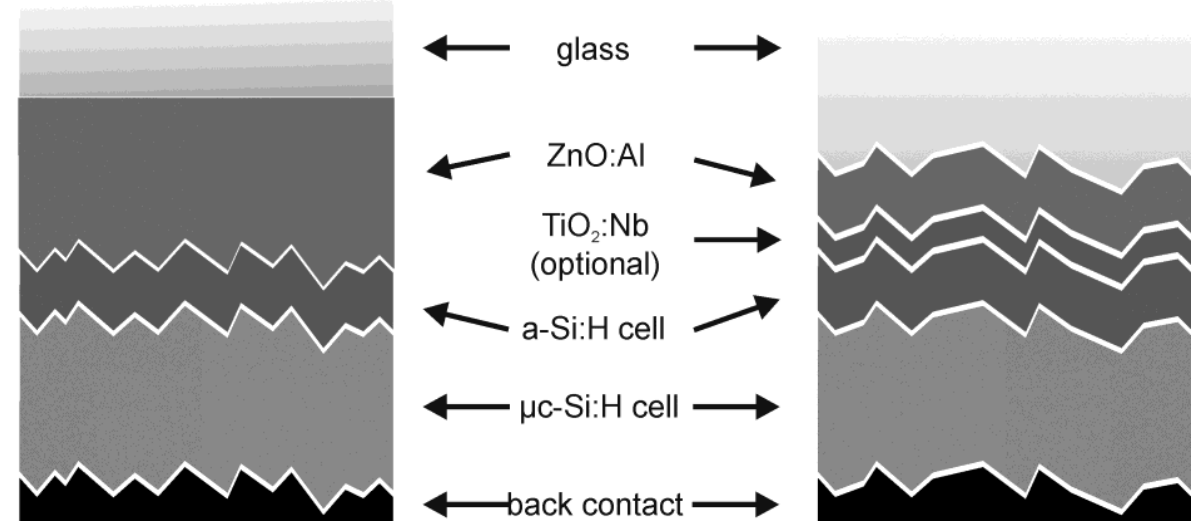

Figure 4: Comparison of a solar cell deposited on textured $\mathrm{ZnO}: \mathrm{Al}$ (left) and textured glass (right). The right design uses a thin $\mathrm{ZnO}: \mathrm{Al}$ layer of solely $250 \mathrm{~nm}$. Optionally an additional TiO:Nb layer was introduced to decrease the reflection at the $\mathrm{ZnO} / \mathrm{Si}$ interface.

The setup of a-Si:H/ $\mu \mathrm{c}-\mathrm{Si}: \mathrm{H}$ tandem cells on conventional etched $\mathrm{ZnO}: \mathrm{Al}$ and on textured glass are shown in figure 4. Light scattering is provided by the rough $\mathrm{ZnO}$ :Al surface in the standard setup (left), while it is mainly influenced by the glass surface in the case of using thin annealed $\mathrm{ZnO}$ :Al on textured glass (right). It should be noted, that the glass substrate exhibits a roughness with much larger feature sizes of around $700 \mathrm{~nm}$ as compared to $200 \mathrm{~nm}$ for the etched $\mathrm{ZnO}: \mathrm{Al}$. Details can be found in [21]. The results showed, that the usage of thick $\mathrm{ZnO}$ :Al layers is not necessary if a suitable texture for light scattering is provided by the substrate. The annealing process not only leads to a suitable sheet resistance even for a thickness of no more than $250 \mathrm{~nm}$, but also decreases the parasitic absorption inside the $\mathrm{ZnO}$ : $\mathrm{Al}$ film. Yet, the cell still suffers from increased cell reflection. This is mainly caused by interference effects which are not completely suppressed by the glass topography and the missing of sub-wavelength sized roughness features, which generally lower the reflectance of the $\mathrm{ZnO}: \mathrm{Al} / \mathrm{Si}$ interface.

In order to decrease cell reflection, an additional $\mathrm{TiO}_{2}: \mathrm{Nb}$ layer was introduced between the front $\mathrm{ZnO}: \mathrm{Al}$ and the amorphous top cell. The layer was deposited with a serial co-sputtering tool that facilitates deposition of component materials with varying composition[22]. In this system niobium is sputtered from a secondary planar target in metallic mode towards a primary rotatable titania target, from where the doped oxide is sputtered onto the substrate in fully oxide mode. With this technique the concentration of niobium can be varied and adjusted accordingly. Further on the oxygen was adjusted in order to get an optimized film quality with high conductivity and low absorption. The as deposited films were afterwards annealed in vacuum to get pure anatas phase and a conductive film. Prior to top cell deposition a $10 \mathrm{~nm}$ $\mathrm{ZnO}: \mathrm{Al}$ layer was deposited onto the titania film in order to protect it from the hydrogen containing plasma used for top cell deposition [23]. 
Table 2: Performance of solar cells on textured glass in comparison to cells on etched $\mathrm{ZnO}$ :Al. Short circuit currents of top cell $\mathrm{j}_{\mathrm{SC}}{ }^{\text {top }}$ and bottom cell $\mathrm{j}_{\mathrm{SC}}{ }^{\text {bottom }}$ were determined from EQE measurements.

\begin{tabular}{|c|c|c|c|c|c|c|}
\hline & $\begin{array}{c}\mathbf{j}_{\mathbf{S C}}{ }^{\text {top }} \\
\mathrm{mA} / \mathrm{cm}^{2}\end{array}$ & $\begin{array}{l}\mathbf{j}_{\mathbf{S C}}{ }^{\text {bottom }} \\
\mathrm{mA} / \mathrm{cm}^{2}\end{array}$ & $\begin{array}{c}\mathbf{j}_{\mathbf{S C}} \\
\mathrm{mA} / \mathrm{cm}^{2}\end{array}$ & $\begin{array}{l}\mathbf{V}_{\text {OC }} \\
\mathrm{mV}\end{array}$ & $\begin{array}{c}\text { FF } \\
\%\end{array}$ & $\begin{array}{l}\eta \\
\%\end{array}$ \\
\hline Etched $\mathrm{ZnO}: \mathrm{Al}$ & 11.1 & 11.4 & 11.3 & 1402 & 72.9 & 11.6 \\
\hline Text. glass & 10.8 & 11.3 & 10.9 & 1393 & 71.9 & 10.9 \\
\hline Text. glass including $\mathrm{TiO} 2$ & 11.6 & 11.2 & 11.6 & 1400 & 69 & 11.2 \\
\hline
\end{tabular}

The cell results obtained on a texture-etched but unannealed $\mathrm{ZnO}: \mathrm{Al}$, a thin annealed $\mathrm{ZnO}: \mathrm{Al}$ film on textured glass and the same stack with an additional $\mathrm{TiO}_{2}: \mathrm{Nb}$ layer are compared in table 2 . The first two cell results are presented in detail in [21]. It can be seen, that the total current collection on the textured glass is slightly inferior to the textured $\mathrm{ZnO}: \mathrm{Al}$ film, despite the higher transmission of the thin $\mathrm{ZnO}$ : Al layer on textured glass. The additional $\mathrm{TiO}_{2}$ layer significantly boost current collection in the top cell, raising the total current of the tandem device over that of the reference cell on textured $\mathrm{ZnO}$ :Al. Furthermore, reflection measurements show room for further improvement. On the contrary the cell suffers from a low fill factor. The sheet resistance of the TCO stack is unlikely to be the cause, as the titania film decreases the resistivity of the TCO further. Nevertheless the cell optics are encouraging and optimization of the titania$\mathrm{ZnO}$ stack continues.

\section{SUMMARY}

It can be summarized that cap annealing is an appealing method to produce high quality $\mathrm{ZnO}$ :Al films with very low resistivity and very small residual absorption. The effects of annealing on carrier concentration can be understood as creation of intrinsic acceptors during annealing in air and annihilation during capped annealing. The effect also explains the strong increase in carrier mobility during cap anneal. No conclusions can be drawn on the influence of intrinsic donors, but it seems marginal for cap annealed samples.

The removal of valence band tails during all annealing processes is not related to acceptor states, but rather seems to be a consequence of annealing of extended defects.

Unfortunately, the high temperatures involved during the cap anneal render the application to HIT or CIGS cells impossible, but the films can be readily applied to solar cells in superstrate geometry. The application to thin film silicon cells was demonstrated. To fully exploit the superior electrical and optical properties of the cap annealed films, textured glass was used as a substrate for cell deposition. This allows the decoupling of light scattering and TCO front contact, allowing the use of very thin films. So far it was demonstrated, that this approach leads to efficiencies at the same level of the well-known process on textured $\mathrm{ZnO}$ :Al. Further optimization of the $\mathrm{TiO}_{2}$ AR layer and the introduction of a small-scale roughness to decrease interference effects could lead to superior cell performance.

\section{ACKNOWLEDGEMENTS}

The partners thank the Federal Ministry for the Environment, Nature Conservation and Nuclear Safety BMU for funding under contract No. 0325299.

\section{REFERENCES}

[1] Paine, D.C., Whitson, T., Janiac, D., Beresford, R., Ow Yang, C., Lewis, B., “A study of low temperature crystallization of amorphous thin film indium-tin-oxide, “Journal of Applied Physics 85(2), 8445 (1999).

[2] Hitosugi, T., Ueda, A., Nakao, S., Yamada, N., Furubayashi, Y., Hirose, Y., Shimada, T., Hasegawa, T., "Fabrication of highly conductive Ti1-xNbxO2 polycrystalline films on glass substrates via crystallization of amorphous phase grown by pulsed laser deposition,“Applied Physics Letters 90, 212106 (2007).

[3] Jahn, R., Löbmann, P., "Microstructure and performance of AZO thin films prepared by sol-gel processing," Journal of Sol-Gel Science and Technology 66, 120 (2013). 
[4] Yu, X., Ma, J., Ji, F., Wang, Y., Zhang, X., Ma, H., "Influence of annealing on the properties of ZnO:Ga films prepared by radio frequency magnetron sputtering," Thin Solid Films 483, 296 (2005).

[5] Chang, J.F., Lin, W.C., Hon, M.H., "Effects of post-annealing on the structure and properties of Al-doped zinc oxide films," Applied Surface Science 183, 18 (2001).

[6] Ahn, B.D., Oh, S.H., Lee, C.H., Kim, G.H., Kim, H.J., Lee, S.Y., "Influence of thermal annealing ambient on Ga-doped ZnO thin films, “ Journal of Crystal Growth 309, 128 (2007).

[7] Ruske, F., Roczen, M., Lee, K., Wimmer, M., Gall, S., Hüpkes, J., Hrunski, D., Rech, B., “Improved electrical transport in Al-doped zinc oxide by thermal treatment, “ Journal of Applied Physics 107, 013708 (2010).

[8] Schönau, S., Ruske, F., Neubert, S., Rech, B., "Analysis of Urbach-like absorption tails in thermally treated ZnO:Al thin films,“ Applied Physics Letters 103, 192108 (2013).

[9] Ruske, F., Wimmer, M., Köppel, G., Pflug, A., Rech, B., "Optical characterization of high mobility polycrystalline ZnO:Al films, “ Proc. SPIE 8263, 826303 (2012).

[10]Lee, K., Becker, C., Muske, M., Ruske, F., Gall, S., Rech, B., Berginski, M., Hüpkes, J., “Temperature stability of ZnO:Al film properties for poly-Si thin-film devices, “ Applied Physics Letters 91, 241911 (2007).

[11] Wimmer, M., Ruske, F., Scherf, S., Rech, B., "Improving the electrical and optical properties of DC-sputtered ZnO:Al by thermal post deposition treatments," Thin Solid Films 520, 4203-4207 (2012).

[12] Look, D.C., Leedy, K.D., Vines, L., Svensson, B.G., Zubiaga, A., Tuomisto, F., Doutt, D.R., Brillson, L.J., "Self-compensation in semiconductors: The Zn vacancy in Ga-doped ZnO," Physical Review B 84, 115202 (2011).

[13]Lany, S., Zunger, A., "Dopability, Intrinsic Conductivity, and Nonstoichiometry of Transparent Conducting Oxides,“"Physical Review Letters 98, 045501 (2007).

[14] Janotti, A., Van de Walle, C.G., "Native point defects in ZnO,“" Physical Review B 76, 165202 (2007).

[15]Ellmer, K., Mientus, R., "Carrier transport in polycrystalline transparent conductive oxides: A comparative study of zinc oxide and indium oxide," Thin Solid Films 516, 4620 (2008).

[16] Sans, J.A., Sánchez-Royo, J.F., Segura, A., Tobias, G., Canadell, E., "Chemical effects on the optical band-gap of heavily doped $\mathrm{ZnO}$ :MIII (M=Al,Ga,In): An investigation by means of photoelectron spectroscopy, optical measurements under pressure, and band structure calculations, “ Physical Review B 79, 195105 (2009).

[17] Schönau, S., Ruske, F., Neubert, S., Rech, B., "Annealing induced changes in optical near-edge properties of Al-doped ZnO thin films, “ E-MRS 2013 Fall Meeting, Warsaw, September 16-20, submitted to p.s.s. (c).

[18] Kaschner, A., Haboeck, U., Strassburg, M., Strassburg, M., Kaczmarczyk, G., Hoffmann, A., Thomsen, C., Zeuner, A., Alves, H.R., Hofmann, D.M., Meyer, B. K., "Nitrogen-related local vibrational modes in ZnO:N,"“ Applied Physics Letters 80(11), 1909 (2002).

[19] Bundesmann, C., Ashkenov, N., Schubert, M., Spemann, D., Butz, T., Kaidashev, E.M., Lorenz, M., Grundmann, M., "Raman scattering in $\mathrm{ZnO}$ thin films doped with Fe, Sb, Al, Ga, and Li," Applied Physics Letters 83(10), 1974 (2003).

[20] Neubert, S., Wimmer, M., Ruske, F., Calnan, S., Gabriel, O., Stannowski, B., Schlatmann, R., Rech, B., "Improved conversion efficiency of a-Si:H/ $\mu \mathrm{c}-\mathrm{Si}: \mathrm{H}$ thin-film solar cells by using annealed Al-doped zinc oxide as front electrode material," Progress in Photovoltaics: Research and Applications, doi: 10.1002/pip.2389 (2013)

[21] Neubert, S., Ring, S., Welker, F., Götzendörfer, S., Ruske, F., Stannowski, B., Schlatmann, R., Rech, B., "Very thin, highly-conductive $\mathrm{ZnO}$ :Al front electrode on textured glass as substrate for thin-film silicon solar cells," physica status solidi - Rapid Research Letters, doi: 10.1002/pssr.201308195 (2013).

[22] Szyszka, B., Dewald, W., Gurram, S.K., Pflug, A., Schulz, C., Siemers, M., Sittinger, V., Ulrich, S., "Recent developments in the field of transparent conductive oxide films for spectral selective coatings, electronics and photovoltaics," Current Applied Physics 12, S2 (2012).

[23] Fujibayashi, T., Matsui, T., Kondo, M., "Improvement in quantum efficiency of thin film Si solar cells due to the suppression of optical reflectance at transparent conducting oxide/ $\mathrm{Si}$ interface by $\mathrm{TiO} 2 / \mathrm{ZnO}$ antireflection coating,“"Applied Physics Letters 88, 183508 (2006). 